\title{
Face Pain, CTCAE
}

National Cancer Institute

\section{Source}

National Cancer Institute. Face Pain, CT CAE. NCI Thesaurus. Code C56075.

Unintended facial pain associated with a medical procedure or administration of a drug. 